\title{
Discussion on Protection, Exploitation and Utilization of Chinese Traditional Civilian House before Yuan Dynasty -A case study of Gaoping Jishi Civilian House
}

\author{
Yaru Tong ${ }^{1, a}$, Xiangdong Zhu ${ }^{*, 2, b}$, Chongen Wang ${ }^{3, c}$ \\ ${ }^{1}$ The Architecture Department of Taiyuan University of Technology, Shanxi Province, China \\ ${ }^{2}$ The Architecture Department of Taiyuan University of Technology, Shanxi Province, China \\ ${ }^{3}$ The Architecture Department of Taiyuan University of Technology, Shanxi Province, China \\ awoshitongzhu@163.com, bzhuxiangdong.@tyut.edu.cn, cwangchongen@tyut.edu.cn \\ (* represents communication author)
}

Keywords: Chinese traditional, Jishi civilian house, Protection, Exploitation and utilization

\begin{abstract}
In this paper, Gaoping Jishi civilian house which is the earliest civilian house of Yuan Dynasty is taken as example (AD 1294), and the current situation material of Jishi civilian house and surrounding environment is obtained and analyzed through field research, then the measure and method of protecting, exploiting and utilizing Chinese traditional civilian house are further proposed. Whether protective measure and utilization method could work need to be discussed and researched more deeply.
\end{abstract}

\section{Introduction}

Jishi civilian house, located in the Zhongzhuang Village of Chenqu District which is 18 kilo meters to the northeast of Gaoping City, is the fourth batch of national key cultural relic protection units, which has only three north rooms left, there are carve characters on the bearing stone of the west door that wrote "(Chinese Character)Da Yuan Guo Zhi Yuan San Shi Yi Nian Sui Ci Zhong $\square \square J i$ Zhai Zhi $\square$ Shi Jiang Tian Dang Jun Feng $\square$ Feng $\square$ ". Jishi civilian house is not only earliest existing civilian house architecture example in China, but also the existing only example of civilian house of Yuan Dynasty, which has high historical value. The original courtyard layout of Jishi civilian house of Yuan Dynasty is unknown, but it can be seen from mural or relic of Yuan Dynasty that the layout of quadrangle courtyard civilian house of Yuan Dynasty is very flexible, which is why the complete layout of courtyard and east and west courtyard formed by existing north room and surrounding civilian house is conductive to the protection and utilization for Jishi civilian house. In addition, other historical factors of ancient village where Jishi civilian house at, such as ancient wells, ancient trees, ancient streets, ancient villages and others, also need to be protected and utilized reasonably. The following is my personal opinion in regard to protection and utilization of Jishi civilian house.

\section{The protection for Chinese traditional civilian house}

The protection for Chinese traditional civilian house should implement the principle of protecting first, rescuing first, strengthening management and utilizing rationally stipulated by The Law of Protection for Cultural Relics of PRC. It includes not only the protection for civilian house architecture, but also the protection for related human culture and historical atmosphere.

\section{Keep original feature of Chinese traditional civilian house}

The original feature of Chinese traditional civilian house, on the one hand, is form and structure that people could sense visually, on the other hand, is construction thought and technology behind it. Although the former is considered to be the carrier for the latter, and form and structure are the specific explanation of construction thought and technology, not all things that are similar to the former can show and demonstrate the latter. Jishi civilian house is the typical Yuan Dynasty 
architecture, which preserves the typical feature and construction technology of Yuan Dynasty architecture as a whole. However, since the descendant had no professional technology and awareness of protecting historical information, overhanging gable roof of Xishan mountain was changed to flush gable roof during repair, and east imbrex roof was changed to concavely upward-facing tile roof, part of wall was not repaired according to original shape after collapse, even though for solid and safety purpose during repair, some structures need to be replaced, but it has to be careful. Because, if object authenticity could not be guaranteed, then it is hard to build the authenticity of thought. Therefore, preserving original architecture form, original architecture structure and original building materials is taken as repair principle for Chinese traditional civilian house, make the best use of original component and materials to keep richer historical information, and guarantee that original feature is still kept after repair and remedy.

\section{Keep culture implication of Chinese traditional civilian house}

Chinese traditional civilian house is historical memory of human survival and development, which reflects the significance on two aspects: first, the form and structure that people could see directly, second, the conception of builder and historical significance that hidden behind architecture. To protect Chinese traditional civilian house, not only protect its architectural appearance, and more importantly, carry on its history and culture. Therefore, strengthen Jishi civilian house cultural and history research, seize context of Jishi civilian house, dig into culture connotation and set propaganda and demonstration of historical information and cultural connotation in the civilian house close to Jishi civilian house. In addition to this, the cultural connotation and cultural evolution of Chinese traditional civilian house not only remains in the ancient architecture of ancestor, but also flows in the local language, folk custom and long real life. There are old Jishi old people aged over 80 still live in Jishi civilian house, whose traditional life style and living environment also demonstrate the original feature of history and culture of Chinese traditional civilian house.

\section{Keep surrounding historical environment and atmosphere of Chinese traditional civilian house}

In the past, limited by understanding and conditions of other aspect, the protection for ancient architecture is mainly limited to those architecture ruins or relics with long history and higher art taste which are listed in the list of protection of cultural relics. As the awareness of historical architecture protection increases, more and more people already feels that certain architectures do not exist isolatedly, and its surrounding environment often plays the role of strengthening or weakening architecture characteristic, therefore, emphasizing protection for feature district and blocks as a whole has gradually become common view, which leads to awareness of protecting ancient city, ancient town, ancient village or historical block.

The east country road of Zhongzhuang Village, the place where Jishi civilian house is located, was originally a river, and the village was located at the highland in the west of river, which reflects the typical thought of Chinese ancient city planning: Building the city upwardly without being close to highland could have enough water, and building the city downwardly without being close to damp and low-lying place could cut out the drainage ditch. There were forts and walls surround the village, and two fort gates in the east, one fort gate in the north and south, which reflects strong defensiveness. Besides Jishi civilian house, many civilian houses from Ming, Qing and Republic of China period are kept in Zhongzhuang village, the historical appearance of whole village are preserved well, and Jishi civilian house and surrounding historical environment has extremely high value of protection. In addition to this, the ancient trees, ancient wells, ancient streets and other historical environment factors at the location of Jishi civilian house are also the witness to history, they can also reflect the local history and culture meticulously, meanwhile, diversified social life of villager and deep deposit of folk custom also show local specific historical atmosphere.

\section{The development and utilization of Chinese traditional civilian house}

Insist on the combination of protection and utilization, make the best use of architectural feature, humanity history and other resource advantages of Chinese traditional civilian house, and develop 
tourism display with Chinese traditional civilian house as typical feature. Historical site is not only the scare resource, but also the non-renewable resource, therefore, it has to be controlled well on the intensity of development and utilization.

\section{Display and utilization}

Make the best use of current conditions to complete the protection and utilization of Jishi civilian house, Jishi civilian house has only three principal rooms left, and it is not conductive to isolated protection for Jishi civilian house if demolish surrounding civilian houses in order to protect historical architecture, therefore, use the complete courtyard layout formed by Jishi civilian house and surrounding civilian house to the layout of courtyard and east and west courtyard which is interconnected with each other while independent. Such as fig 1, surrounding residential areas is transformed into display and service room that are related to Jishi civilian protection. To make people know the historical status and cultural value of Jishi civilian house by displaying general layout of Jishi civilian house, space organization, architecture scale relation, architectural type, structural mode and others, combining special status and significance of Jishi civilian house and displaying real object, words, picture, material and others that are related to Zhongzhuang Village history, cultural customs and etc. Meanwhile, publicize and popularize the knowledge of cultural relic protection, improve awareness and level of cultural relic of the whole nation and promote foreign and domestic academic exchanges by displaying the way, method, technology and process of historical architecture protection.

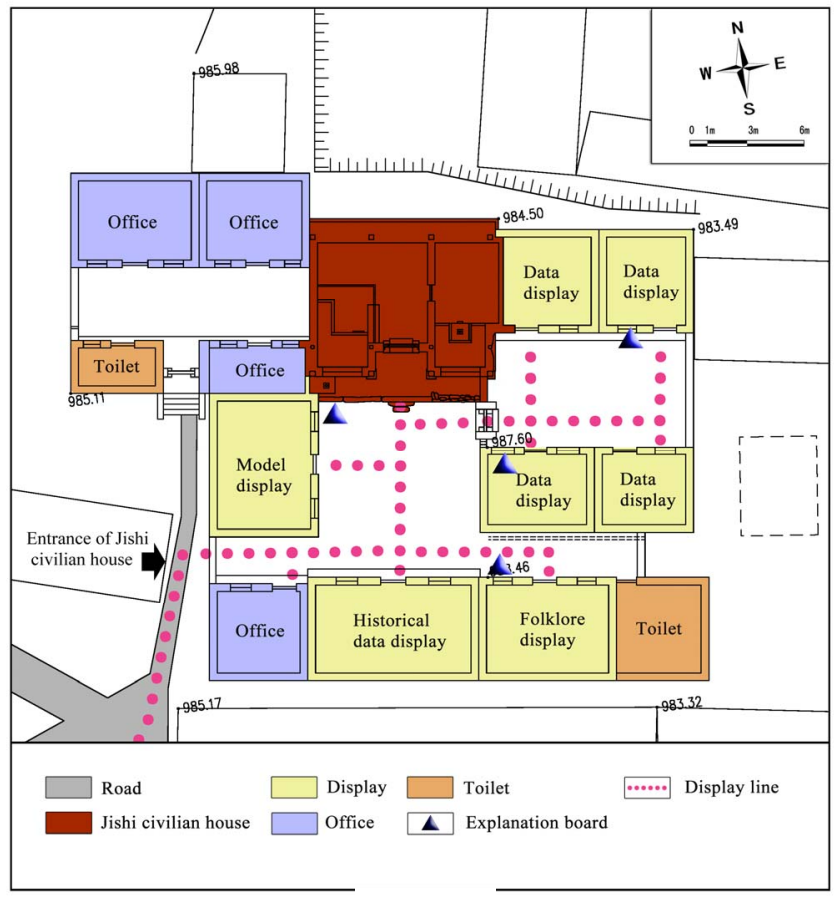

Fig 1

\section{Innovation and utilization}

Displaying and demonstrating the traditional architecture handed down by ancestors is the best way to fully play its role, but in a city, what needs to be displayed, demonstration place and quantity are limited, it is not possible to turn all Chinese traditional civilian house into exhibition hall, however, the protection for traditional architecture needs large sum of money, if these architectures are unable to play their role, the enthusiasm of protection would be affected. Such as fig 2, this is historic residences route exhibition in Zhongzhuang Village.The civilian houses from Ming, Qing and Republic of China period around Jishi civilian house were originally silks and satins shop, flour mill and others, therefore, besides setting showroom, the original function of other civilian houses could be recovered, which reproduces original marketplace cultural style in history, and shows long history, culture, folk custom and style of ancient village as well. Allow more people to use in a way of helping traditional civilian house at the brink of being protected to make benefit. Moreover, make traditional cultural characteristic old famous brand back into street and open, set up utensil display 
and workshop exhibition and build traditional cultural atmosphere meticulously to refresh tourists. Meanwhile, add the exhibition of folk handcraft and other non-material cultural heritages. Chinese traditional civilian house through rational development and utilization should be living organism, not the display in museum. The protection for Chinese traditional civilian house has to make ancient room filled with the flavor of life, with dynamic and development point of view, only creatively developed protection and utilization mode could inject new vitality into ancient architecture.

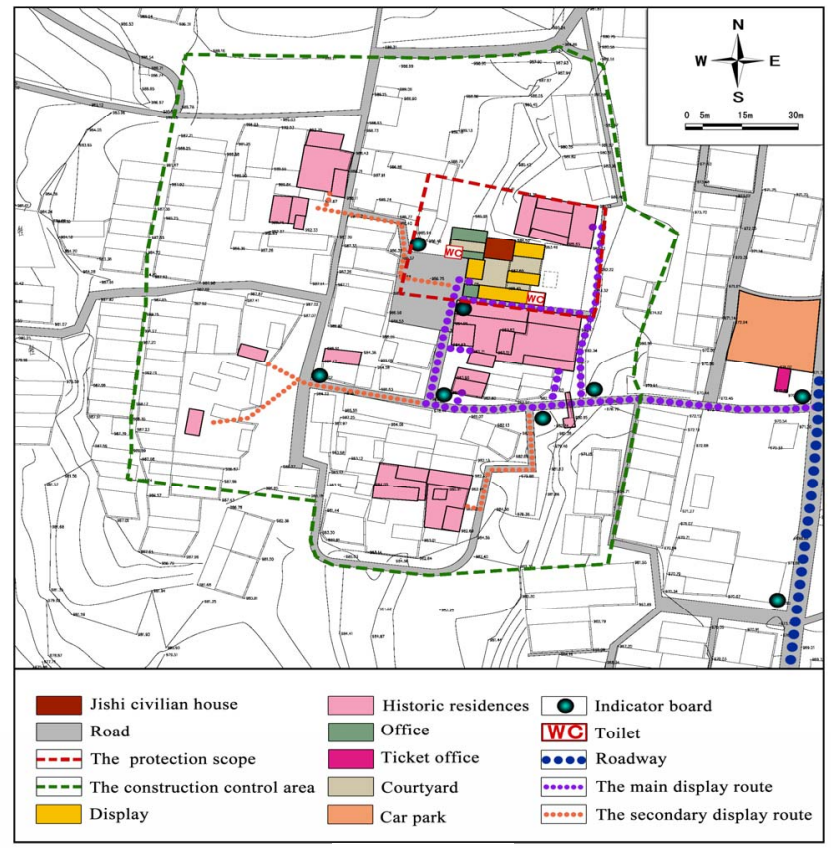

Fig 2

\section{Conclusion}

In conclusion, Chinese traditional civilian house carries the deposit of thousands of years of history and culture of China, which has important value and significance to research architecture, folk custom, culture and religion. Therefore, under the trend of fast economic development, the relationship between protection and utilization need be handled correctly, and effective method should be applied to make the protection for Chinese traditional civilian house and development of tourism industry promotes each other to form positive cycle.

\section{Acknowledgment}

Fund project: Floor type stone arch cave dwelling settlement shape and research on protection and utilization. National Youth Fund Project.(Serial number: 51108294 )

\section{References}

[1] Z.W.Luo, Ancient Chinese Architecture, revised edition[M]. Shanghai: Shanghai Classics Publishing House, 2001

[2] S.Q.Chen, The research on Ancient Civilian House Protection Problem, Henan Science \& Technology, 2011.

[3] A.H.Luo, Z.Zhu, Tactics of conservation and development of ancient folk houses-Taking folk houses in Zhenjiang Xijin Ferry as an example, Zhenjiang College Journal. Oct, 2008, pp 11 14.

[4] B.Chen, The Principles Of Protection And Updattion to Traditional Town, Journal of Guizhou University(Natural Science Edition),2009, pp 108 110.

[5] X.J. Liu, Fresh ideas on Conservation and Exploitation of Local-style Dwelling House, Architecture \& Culture, 2006,pp74 79. 